\title{
MAGNETICALLY PLUCKED PIEZOELECTRIC ENERGY HARVESTER VIA HYBRID KINETIC MOTION
}

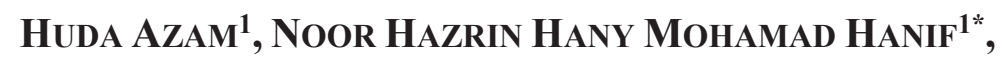 \\ AND Aliza Aini Md RaliB ${ }^{2}$ \\ ${ }^{1}$ Department of Mechatronics Engineering, \\ ${ }^{2}$ Department of Electrical and Computer Engineering, \\ International Islamic University Malaysia, \\ P.O. Box 10, Kuala Lumpur 50728, Malaysia. \\ *Corresponding author: noorhazrin@iium.edu.my

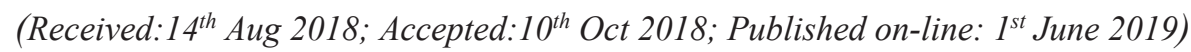 \\ https://doi.org/10.31436/iiumej.v20i1.981
}

\begin{abstract}
Piezoelectric energy harvesting is a possible breakthrough to reduce the global issue of electronic waste as they can efficiently convert the ambient vibration to the electrical energy without any additional power. This work presents the design and development of a piezoelectric energy harvester that is capable of transforming vibration from ambient sources into electricity. It focuses on a magnetically plucked piezoelectric beam as an alternative to the mechanically induced harvesters, as the latter are subjected to wear and tear. A prototype comprising of a $40 \mathrm{~mm}$ PZT-5H piezoelectric beam with a permanent magnet mounted at one end of the beam, as well as a series of permanent magnets of same types attached on an eccentric rotor was developed along with a National Instruments ${ }^{\circledR}$ data acquisition device. Mean output voltages of $2.98 \mathrm{~V}, 1.76 \mathrm{~V}$ and $0.34 \mathrm{~V}$ were recorded when the eccentric rotors were slowly rotated at $8.4 \mathrm{rad} / \mathrm{s}$ with increasing distances of $5 \mathrm{~mm}, 7.5 \mathrm{~mm}$ and $10 \mathrm{~mm}$ respectively, between the magnets on the rotor and the beam. These results have proven that voltage could also be generated by magnetically plucking the piezoelectric beam, and by reducing the distance between magnets, the amount of voltage generated will be higher. The outcome of this work signifies the possibility for implementation of energy harvesters that are capable of powering electronic devices from hybrid kinetic motion, with a reduced risk of equipment fatigue.
\end{abstract}

ABSTRAK: Penjanaan tenaga melalui piezoelektrik adalah satu penemuan terbesar dalam mengurangkan isu global pengurusan sisa elektronik. Ini kerana ia berupaya mengubah getaran persekitaran kepada tenaga elektrik tanpa sebarang tambahan tenaga. Kajian ini berkenaan reka bentuk dan pembangunan penjana tenaga piezoelektrik yang mampu mengubah getaran persekitaran kepada elektrik. Fokus kajian adalah pada penjanaan tenaga secara magnetik dari bilah piezoelektrik sebagai alternatif kepada penjanaan mekanikal, kerana penjanaan tenaga secara mekanikal berisiko tinggi kepada kerosakan alat dalam jangkamasa panjang. Prototaip piezoelektrik PZT-5H yang berukuran $40 \mathrm{~mm}$ ini telah dilengkapi magnet kekal pada hujung bilah, serta satu siri magnet kekal jenis sama turut dipasang pada pemutar eksentrik bersama peranti pengambilan data National Instruments ${ }^{\circledR}$. Secara purata, sebanyak $2.98 \mathrm{~V}, 1.76 \mathrm{~V}$ dan $0.34 \mathrm{~V}$ voltan output telah direkodkan ketika pemutar eksentrik berputar perlahan pada $8.4 \mathrm{rad} / \mathrm{s}$ dengan jarak tambahan antara magnet pemutar dan bilah piezoelektrik bersamaan $5 \mathrm{~mm}, 7.5 \mathrm{~mm}$ dan $10 \mathrm{~mm}$, masing-masing. Keputusan menunjukkan tenaga dapat dihasilkan dengan cara pemacuan piezoelektrik secara magnetik, dan tenaga yang 
terhasil akan bertambah dengan pengurangan jarak antara magnet. Hasil kerja menunjukkan tenaga dapat dihasilkan daripada gerakan kinetik hibrid, dengan risiko rendah pada kerosakan alat.

KEYWORDS: piezoelectric; energy harvester; hybrid kinetic motion; magnetically plucked

\section{INTRODUCTION}

The increasingly exorbitant amount of discarded electrical and electronic waste (ewaste) has become a global issue that demands immediate attention. Among the largest contributors of e-waste are batteries, which are commonly found in portable electronic and wearable devices. These batteries contain toxic materials that pose threats to health and the environment if not handled properly. As the demand for portable power-consuming products rapidly increased over the years, an urgent need to find an alternative power supplies developed. One solution is to develop self-powered devices that are capable to generate enough electricity to power up electronic devices using only kinetic motion.

One of the most researched topics, especially when it comes to energy harvesting in wearable devices, is the conversion of mechanical kinetic energy into electrical energy. The kinetic energy (K.E), which is also called the energy of motion of an object, is dependent upon the square of the velocity, as revealed by the following equation;

$$
\mathrm{K} . \mathrm{E}=0.5 \cdot m \cdot v^{2}
$$

where $m$ and $v$ are the mass and the velocity of object respectively.

By this kind of conversion, the kinetic energy can be transferred into electrical energy, by way of electrostatic, electromagnetic and piezoelectric conversion principles [1]. In electrostatic energy harvesters, relative motion between two plates of a variable capacitor structure generates electrical charges. These capacitor plates need to be precharged; hence a separate voltage source is required. The electromagnetic energy harvesting method involves generation of electromagnetic induction current through the relative motion of magnets and a coil. Piezoelectric energy harvesters convert mechanical energy into electrical by straining piezoelectric materials under loaded force due to direct piezoelectric effect. A comparative study of electromagnetic and piezoelectric energy harvesters have been reported in [2]. It shows that piezoelectric energy harvesters produce higher power density as compared to electromagnetic energy harvester thus are more suitable for microsystems [2].

A knee-joint energy harvesting device named Pizzicato Energy Harvester has been developed by works reported in $[3,4]$. The device is secured by braces and worn on the outer side of the knee. Sixteen piezoelectric bimorphs house on a single hub were mechanically plucked by the ring-mounted plectra as the joint rotated during walking and running $[3,4]$. The design was then improved by substituting the mechanical plucking mechanism with a magnetic plucking mechanism to maintain the durability of the device. The magnetic plucking mechanism was implemented using primary magnets and fixing secondary magnets on the bimorph tip. Whenever there is a motion by the knee-joint, a magnetic attraction or repulsion happens between these primary and secondary magnets. Thus, the magnetic attraction or repulsion excites the piezoelectric bimorphs $[5,6]$. An increase in power output generation from $1.9 \pm 0.12$ to $4.5 \pm 0.35 \mathrm{~mW}$ has been reported as the speed increased from 3 to $7 \mathrm{~km} / \mathrm{h}$. The generated power was able to power a wireless sensor network to work at duty cycles from $6.6 \pm 0.36 \%$ to $13 \pm 0.5 \%$ with an active time of $2.0 \pm 0.1 \mathrm{~s}[7]$. 
A quite similar magnetic plucking approach is employed for a wearable device with a pendulum and a piezoelectric transducer [8]. Two permanent magnets were used in this work, in which one was attached to the tip of the piezoelectric beam and another one was attached to the rotor. When the rotor swings under linear and rotational excitation, the two magnets attract each other at each pass. This causes the beam to bend until it gets released, as the bending force surpasses the magnetic attraction. At a frequency of $2 \mathrm{~Hz}, 2.6$ microwatt power was reached when tested using a rocking table [8]. A maximum power output of $1314 \mu \mathrm{W}$ could be produced by configuring multiple magnets at various polarity and positions, which is sufficient to power up low-powered devices [9].

The higher the speed of the motion, the more kinetic energy is produced. Hence, the higher electricity can be transduced due to the piezoelectric effect. As illustrated in Fig. 1, kinematic motion mechanisms can be broadly classified into three categories, which are rotational, oscillatory, and hybrid [10]. Rotational devices are driven by continuous rotational power. For energy harvesting purposes, this kinetic motion mechanism is not suitable since it needs a steady driving torque. Linear oscillatory devices are driven in resonance by forced vibration. It utilizes the mass-spring damper system design, such that the mass oscillates linearly under the influence of external forces such as gravity. One disadvantage of this mechanism is that it is limited by the end of the strokes.

Likewise, hybrid devices also rely on external forces. Hybrid devices are able to convert linear motion into rotational motion using an imbalanced eccentric rotor. Under gravity and rotational excitation, the rotor behaves like a pendulum. This makes it suitable for human-induced motions which are known for their low frequency and aperiodic and irregular characteristics. A simulation of a rotor motion has been reported in [11]. It is found that the rotor can complete one full rotation purely due to inertia and excited up to 4 $\mathrm{Hz}$ [11]. Due to the dynamic behaviour and the low frequency of ambient kinetic motion in general, the hybrid kinetic motion mechanism is deemed to be the most suitable choice compared to other kinetic motion mechanisms.

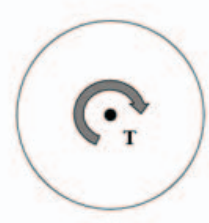

(a)

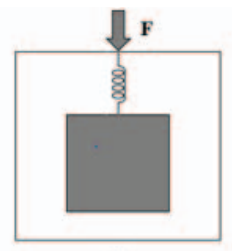

(b)

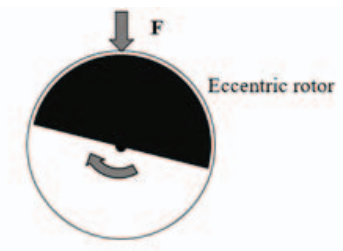

(c)

Fig. 1: Three different types of kinetic motion mechanism:

(a) rotational, (b) linear oscillatory and (c) hybrid

Previously, we designed a prototype that utilized only rotational movement in harvesting piezoelectric energy. In this design, a specially fabricated rotational piezoelectric energy harvester prototype that consisted of a $40 \mathrm{~mm}$ piezoelectric beam that mechanically plucked poles on an eccentric rotor and aluminium proof-mass was developed. With this prototype, the maximum voltage output of $0.024 \mathrm{~V}$ was recorded at the vibration frequency of $18 \mathrm{~Hz}[12,13]$.

This initial design, however, only managed to generate approximately $0.8 \%$ of mean voltage required to operate a portable electronic device. Furthermore, the device was dependent on mechanical plucking, in which the piezoelectric beam was continuously in contact with rotor pins during rotation. This increased the possibility of wear and tear for both rotor pins and piezoelectric beam. Provided with a proper eccentric rotation mass 
design, the implementation of magnetically plucked piezoelectric harvester may be capable to reduce the risk of equipment fatigue as contact between the beam and rotor pins are eliminated.

Additionally, mechanical plucking also causes power inefficiency. It was reported in works by Pozzi $[14,15]$, that there was a $40 \%$ power loss via this method, which was due to the contact friction during which the piezoelectric beam was consistently deflected. As magnetic forces can still produce sharp plucking in the absence of contact friction, we adopted a magnetic plucking approach as an alternative approach to mechanical plucking. This method is expected to increase the durability and power efficiency of the device. The proposed device was simulated using Finite Element Method (FEM) to determine the most suitable piezoelectric material.

For experimental setup, a series of five permanent magnets, attached on a specially fabricated eccentric rotation mass was utilized to initiate magnetic plucking on the piezoelectric beam (with a permanent magnet mounted at one end of the beam) that induces transduction from vibration to electricity. As the magnets repel and attract each other due to their polarities, the amount of vibration to the piezoelectric beam should increase towards its resonance frequency, according to the following formula:

$$
f_{r}=\frac{v \prime_{n}^{2}}{2 \pi L^{2}} \sqrt{\frac{K}{m_{e}+\Delta m}}
$$

in which $f_{r}$ is resonant frequency, $L$ is the beam length, $K$ is the effective spring constant of the cantilever beam, $v_{n}=1.875$ is the eigenvalue for the fundamental vibration, $v_{n}^{\prime 2}=v_{n}^{2} \sqrt{0.236 / 3}, \Delta m$ is the proof mass, $m_{e}=0.236 m w L$ is the effective mass of the cantilever while $m$ is mass per unit length of the beam and $w$ is width of the cantilever.

The electrical circuit and power produced by a cantilever piezoelectric beam have been represented and derived by Lefeuvre, et al [16]. The equation used for the average power, $\mathrm{P}$, produced by the energy harvester is as follows:

$$
P=\frac{R \alpha^{2}}{\left(R C_{p} \omega_{r}+\left(\frac{\pi}{2}\right)\right)^{2}} \frac{M^{2} \omega_{r}^{4} U_{1}^{2}}{\left(C_{v}+\left(2 R \alpha^{2} /\left(R C_{p} \omega_{r}+\left(\frac{\pi}{2}\right)\right)^{2}\right)\right)^{2}}
$$

where $M$ is the magnitude of the harvester's base acceleration, $\mathrm{R}$ is load resistance, $\mathrm{U}$ is sinusoidal mechanical displacement, $\omega_{r}$ is resonance angular frequency, $\propto$ is the electromechanical coupling properties of piezoelectric materials and $C_{v}$ and $C_{p}$ are dampers coefficients for mechanical and electrical parts respectively.

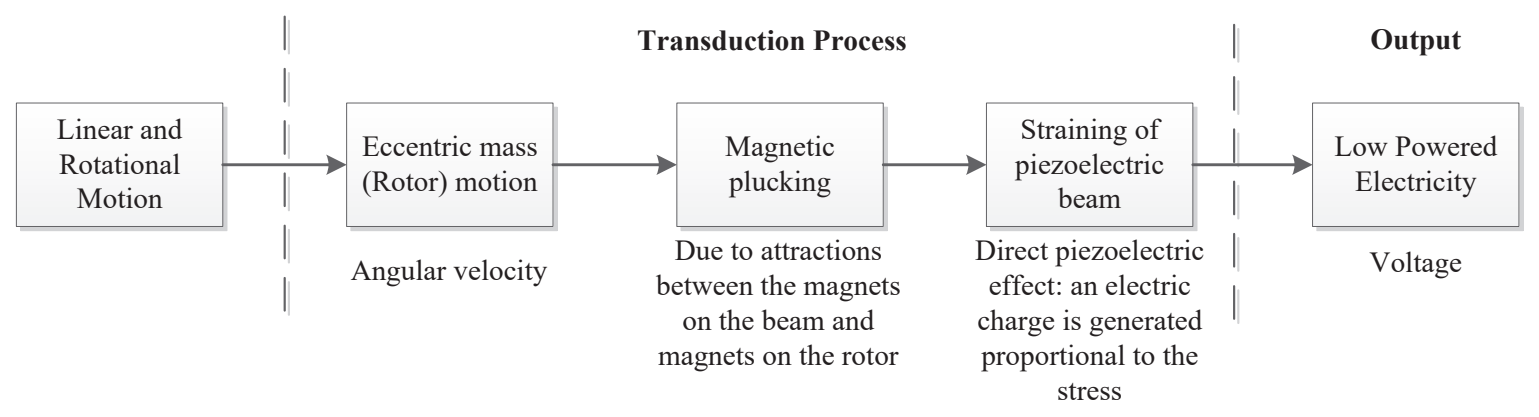

Fig. 2: Overview of the research framework.

Figure 2 shows the framework of this research at a glance. The inputs to the system are linear and rotational kinetic motion with frequencies between 20 to $200 \mathrm{~Hz}$. When the 
rotor swings and passes through the beam, the attraction and repulsion between the magnets on the rotor and the ones on the beam will excite vibrations on the beam. The straining of the piezoelectric beam due to plucking will produce low-powered electricity.

\section{SYSTEM DESIGN AND METHODS}

The selected piezoelectric beam for this work is a $40 \times 10 \times 0.5 \mathrm{~mm}$ (length, width, thick) PZT-5H piezoelectric beam. Based on our previous work, PZT-5H has produced the highest output voltage as compared to other piezoelectric beams [12]. The beam is a bimorph structure, where two thin layers of piezoelectric materials are bonded onto the same metal layer. By this stacking approach, the power output is doubled with minimal increase in the device volume. Besides, it also produced a higher output current with lower impedance to match the impedance of electrical devices [17].

\subsection{Configuration of the Piezoelectric Beam}

The piezoelectric beam is configured by a layer of copper sandwiched between two active layers of the piezoelectric materials. To produce large mechanical strain, we utilize cantilever geometry, in which one of the piezoelectric beam ends is anchored to the hosting structure while a proof mass $(0.71 \mathrm{~g}$ of Neodymium iron Boron $(\mathrm{NdFeB}))$ is mounted at the other end of the beam. Fig. 3 shows the piezoelectric cantilever structure while Table 1 shows the properties of each material.

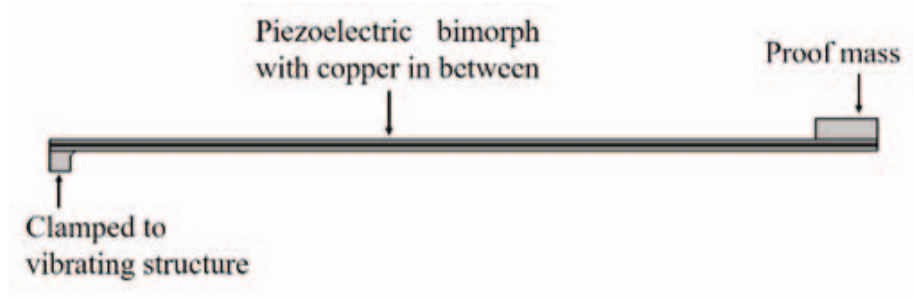

Fig. 3: Model geometry of piezoelectric cantilever beam.

Table 1: Properties of each material of the cantilever beam

\begin{tabular}{lllll}
\hline Material & Symbol & $\begin{array}{l}\text { Density, } \\
\rho\left[\mathbf{k g} / \mathbf{m}^{3}\right]\end{array}$ & $\begin{array}{l}\text { Electrical } \\
\text { conductivity } \\
{\left[\mathbf{S m}^{-1}\right]}\end{array}$ & $\begin{array}{l}\text { Poisson's } \\
\text { Ratio, } \mathbf{v}\end{array}$ \\
\hline Lead Zirconate Titanate & $\mathrm{PZT}-5 \mathrm{H}$ & 7800 & - & 0.31 \\
Neodymium iron Boron & $\mathrm{NdFeB}$ & 7500 & $10 \times 10^{6}$ & 0.24 \\
Copper & $\mathrm{Cu}$ & 8960 & $59.8 \times 10^{6}$ & 0.35 \\
\hline
\end{tabular}

The choice of the piezoelectric material is very crucial to ensure the optimum output voltage and power produced. To verify that we have chosen an optimum piezoelectric material, we carried out a series of simulations using COMSOL Multiphysics ${ }^{\circledR}$ simulation software to study the voltage and power output with respect to vibration frequency and electrical load resistance. Four different piezoelectric materials were simulated: lead zirconate titanate $\left(\mathrm{Pb}[\mathrm{Zr}(\mathrm{x}) \mathrm{Ti}(1-\mathrm{x})] \mathrm{O}_{3}\right)$ (also known as $\left.\mathrm{PZT}\right)$, polyvinylidene difluoride (PVDF), aluminium nitride (AlN) and Barium Sodium Niobate $\left(\mathrm{Ba}_{2} \mathrm{NaNb}_{5} \mathrm{O}_{15}\right)$. The resonance frequency of the maximum displacement of vibration was predicted using finite element analysis. It was shown that maximum displacement will provide a maximum output power from the piezoelectric energy harvester [18]. 
Figure 4(a) illustrates the simulated output voltage as a function of vibration frequency. The voltage is maximum at a specific frequency where it is called the resonance frequency. In low frequency applications, it is desirable to achieve the resonance at low frequency as well as getting sufficient output voltage at that point of frequency. PVDF has the lowest resonant frequency, which is at $40 \mathrm{~Hz}$ only. However, as PVDF is a kind of piezoelectric polymer, it has much lower piezoelectric constants. This explains the small amount of its voltage output, which is only $0.41 \mathrm{~V}$. At $312 \mathrm{~Hz}$, PVDF has the second resonant frequency but the output voltage is still low, which is $0.67 \mathrm{~V}$. PZT-5H has the second lowest resonant frequency, which is at $141 \mathrm{~Hz}$, with the highest maximum output voltage of $4.1 \mathrm{~V}$. Barium sodium niobate yields output voltage of $7.9 \mathrm{~V}$ at $256 \mathrm{~Hz}$, and lastly at $356 \mathrm{~Hz}$ aluminium nitride yields the output voltage of $6.7 \mathrm{~V}$. Hence, PZT-5H was chosen as the piezoelectric material due to high output voltage of $4.1 \mathrm{~V}$ at low resonant frequency of $141 \mathrm{~Hz}$.

The electrical power output was then measured as a function of the electrical load resistance as shown in Fig. 4(b). An acceleration of $1 \mathrm{~g}$ was applied, vibrating at the materials' respective resonant frequencies. For the range of 0.1 to $100 \mathrm{k} \Omega$, the peak power of $0.65 \mathrm{~mW}$ was harvested for PZT-5H material.
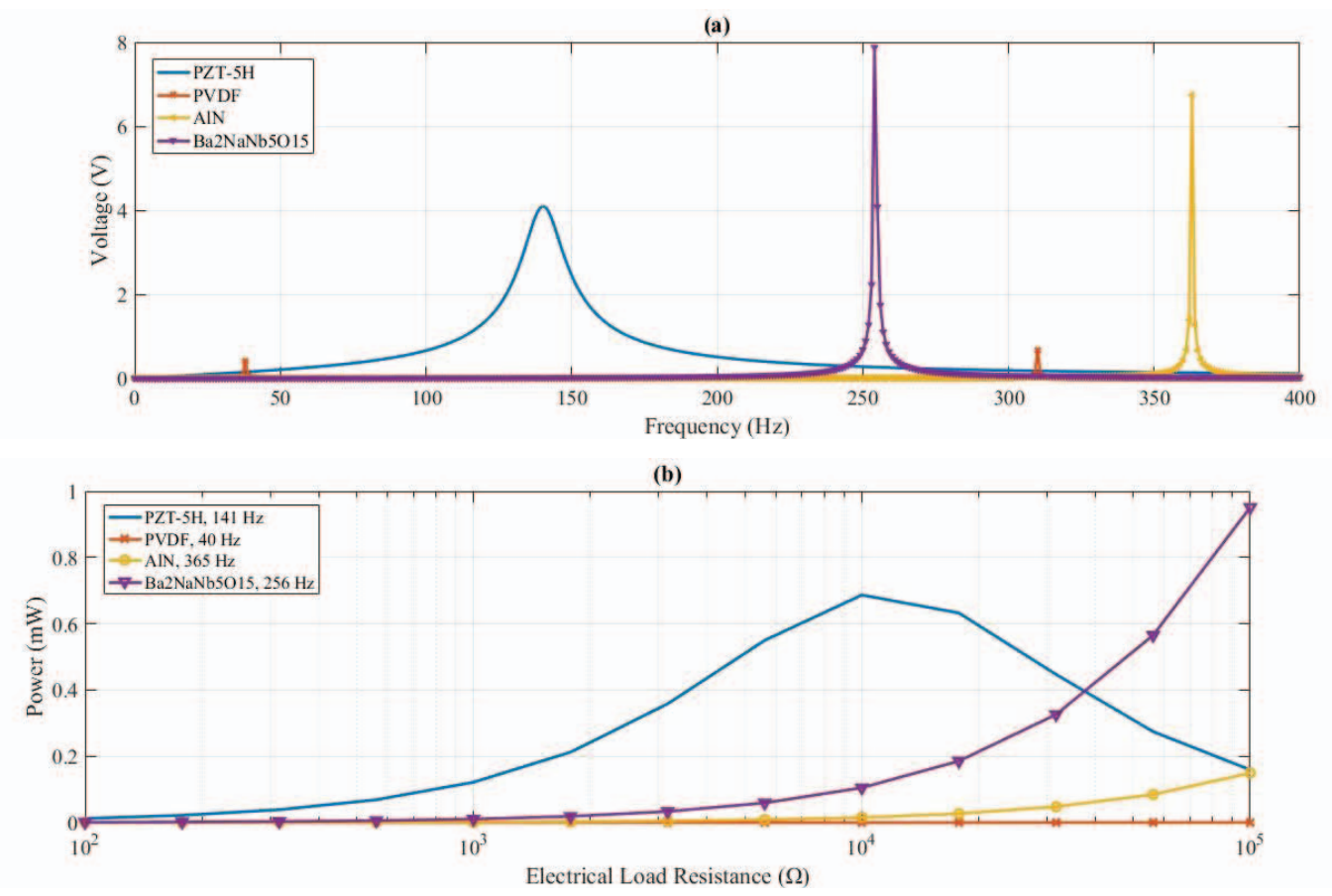

Fig. 4: Comparison of different materials' (a) voltage output as a function of frequency, (b) power output as a function of electrical load resistance.

Based on the simulations, the PZT-5H is chosen to be the most suitable for this application. The decision was made based on its capability to achieve a targeted voltage of $3 \mathrm{~V}$ at a lower resonant frequency as compared to other materials. To achieve its resonant frequency of $141 \mathrm{~Hz}$, large excitation is needed in order to achieve the desired voltage output. Human movements are only able to generate low frequency vibrations between 0.1 $\mathrm{Hz}$ to $25 \mathrm{~Hz}$ [19], thus we incorporated the rotational motion of an eccentric motor with the linear motion from a cantilever beam (hybrid kinetic) to produce an attainable output. This can be done with the plucking technique, whereby the low frequency excitation is coupled into a transduction mechanism that operates at its natural frequency [17]. 
Henceforth, the right kinetic motion mechanism that can produce optimum plucking is essential.

\subsection{Configuration of the Hybrid Kinetic motion Energy Harvester}

In our previous design, we fabricated a compact prototype that could harvest electricity from a $40 \mathrm{~mm}$ piezoelectric beam with the aid of a rotating rotor. The specially designed rotor obtained its rotational motion from a step vibration input of $18 \mathrm{~Hz}$. With this prototype, a maximum voltage output of $0.024 \mathrm{~V}$ was recorded [12]. We improved our previous design by substituting the poles attached on the rotor with Neodymium iron boron $(\mathrm{NdFeB})$ permanent magnets. This way, the beam will not be subjected to mechanical plucking and this will improve the durability of the device.

The configuration of the hybrid kinetic motion energy harvester is shown in Fig. 5. Similar to the previous design, it consists of a PZT-5H piezoelectric beam. One end of the piezoelectric beam is clamped while the other end is mounted with a permanent magnet that acts as a proof mass to the cantilever structure. As shown in Fig. 5, the permanent magnet (shaded in orange) is mounted on the piezoelectric beam while the rest of the magnets are mounted on the eccentric rotation mass. The eccentric rotation mass is placed at an adjustable distance up to $10 \mathrm{~mm}$ (in y-axis direction) from the piezoelectric beam.

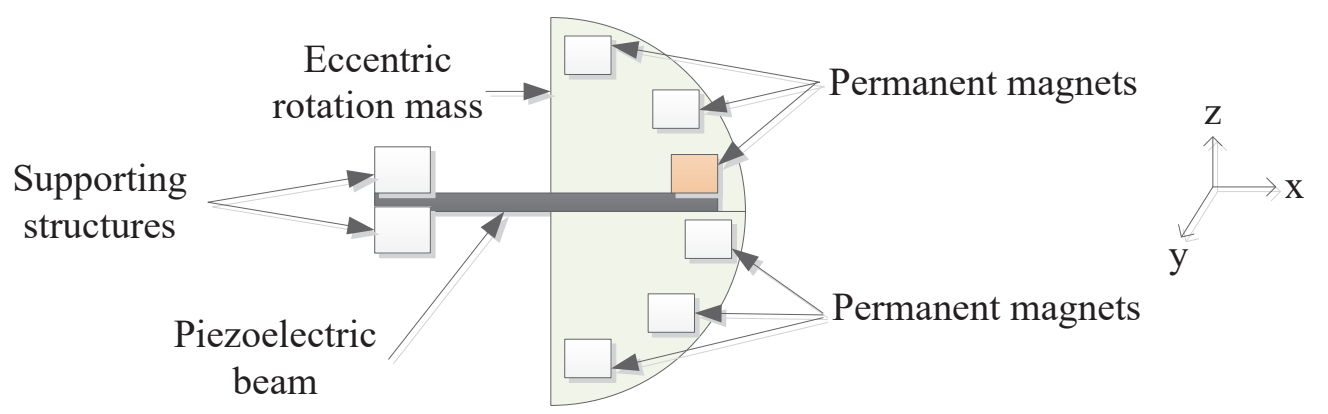

Fig. 5: Configuration of the hybrid kinetic motion energy harvester.

Figure 6 shows the design of the fabricated energy harvester. One end of the beam is clamped to the casing and while the cantilevered end is mounted with one $\mathrm{NdFeB}$ permanent magnet. Another five $\mathrm{NdFeB}$ permanent magnets are glued to the eccentric rotation mass. The $\mathrm{NdFeB}$ strong permanent magnets were chosen because they are widely available, cost effective, and relatively easy to machine. The masses of each magnet and of the piezoelectric beam are $0.71 \mathrm{~g}$ and $1.60 \mathrm{~g}$, respectively. These components are put together in a circular plastic casing with an inner diameter of $5.2 \mathrm{~cm}$. An aluminum bearing is fixed to the assembly to allow the rotation of the eccentric mass rotor.

The eccentric rotation mass is included in this design to yield an even higher vibration output to the piezoelectric beam. As the mass continuously rotates, it produces an asymmetric centripetal force with a net centrifugal force that causes vibration to the beam. At the same time, the vibration is further increased by the attractions and repulsions of the permanent magnets at both the eccentric mass and the piezoelectric beam. The combined vibration outputs should drive the frequency of vibration of the piezoelectric beam towards its resonant frequency. This will in turn produce a higher voltage output from the harvester. 


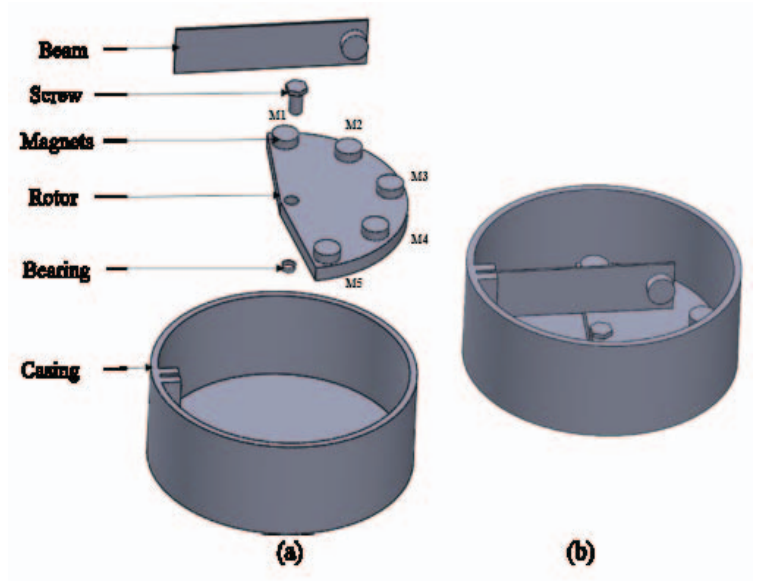

Fig. 6: The hybrid kinetic motion energy harvester:

(a) exploded view, (b) final assembly.

\subsection{Experimental set-up for voltage output measurement}

Figure 7 shows the experimental setup of the fabricated energy harvester in measuring the output voltage. The apparatus for the experiment includes a dc geared motor, an Arduino Uno microcontroller to control the pulse width modulation (PWM) of the motor, and a $10 \mathrm{~A}$ DC motor driver (MD10C) to drive the motor according to the PWM signals. For monitoring and data logging purposes, the National Instruments ${ }^{\circledR}$ USB6211 data acquisition device and LabVIEW® software were utilized. The sampling frequency for this data acquisition was set at $1000 \mathrm{~Hz}$.

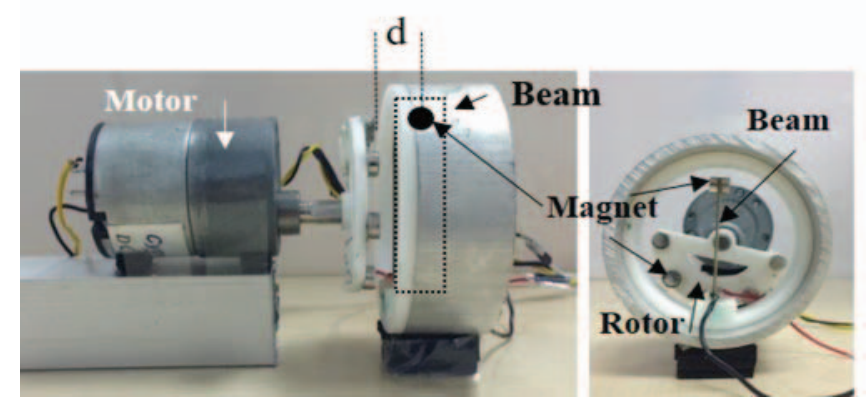

Fig. 7: (a) Side and (b) front view of the experimental setup for optimization of distance, $\mathrm{d}$ between magnets.

To begin the experiment, the distance, $d$, between the magnet at the piezoelectric beam and the magnets at the eccentric rotation mass was measured and positioned accordingly. In the initial voltage output measurement, the dc motor was rotated at a speed of $80 \mathrm{rpm}(8.4 \mathrm{rad} / \mathrm{s})$, with the distance between magnets set at $5 \mathrm{~mm}$. The distances were then inceased to $7.5 \mathrm{~mm}$ and finally at $10 \mathrm{~mm}$, to observe the generated voltage outputs. Throughout the experiment, the dc motor maintained its low, constant speed of $8.4 \mathrm{rad} / \mathrm{s}$.

\section{EXPERIMENTAL RESULTS}

As the eccentric mass (rotor) rotated and passed through the anchored beam, the attraction between magnets on the rotor and magnets on the beam caused straining of the piezoelectric beam. At the same time, the asymmetric centripetal force due to the rotation of the eccentric mass causes the piezoelectric beam to further vibrate. Accordingly, output voltage was induced. The output voltage was recorded based on varying the distance, $d$, 
between magnets on the beam and magnets on the rotor. The distance was measured perpendicularly at $5 \mathrm{~mm}, 7.5 \mathrm{~mm}$, and $10 \mathrm{~mm}$, which from this point onwards will be denoted as D1, D2, and D3, respectively.

Figure 8 highlights the resulting output voltage in time domain for the three readings. It could be observed that in one full cycle of the output waveform, five voltage peaks were evident. These five voltage peaks are the voltage induced as the piezoelectric beam was magnetically plucked by the five magnets attached at the eccentric mass rotor. As the rotor has the shape of a semi-circle, the voltage peaks induced via the magnetic plucking were present in the half cycle of the waveform.
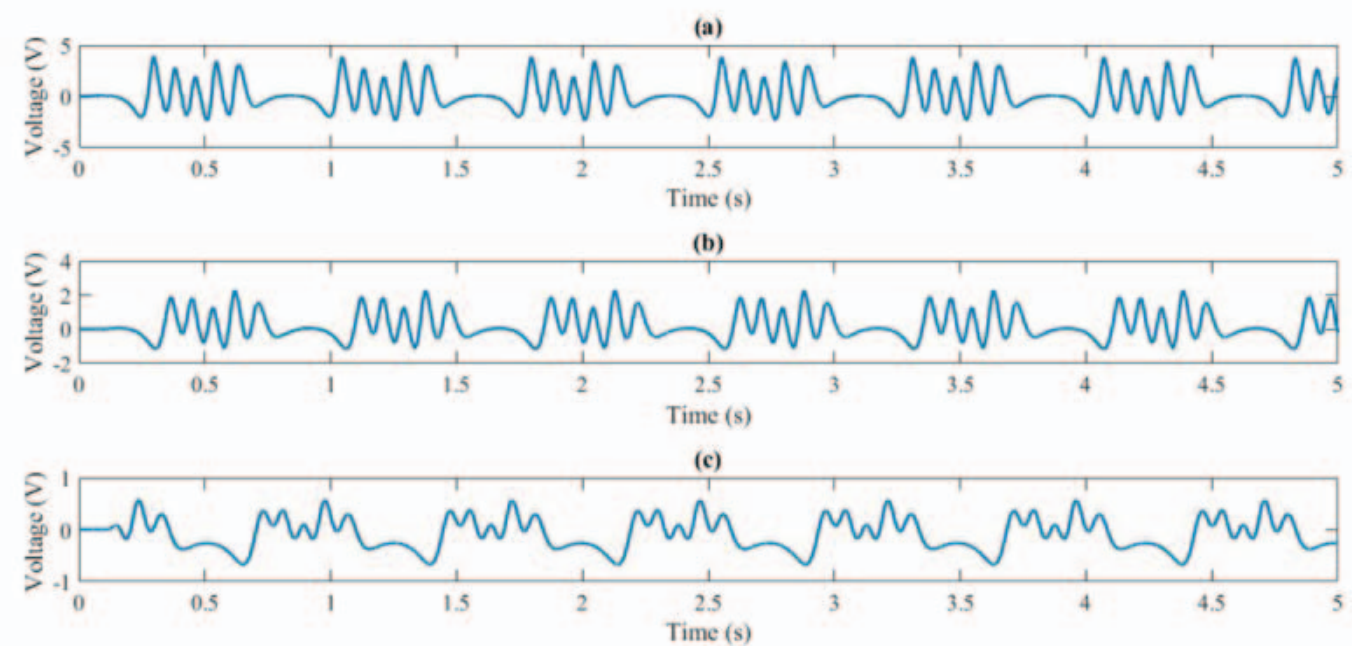

Fig. 8: Voltage output of PZT beam with distance between magnets at

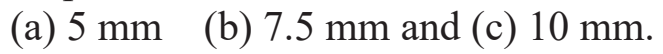

By comparing the results among the three setups, it could be gathered that the highest voltage induced was when the magnets were separated by $5 \mathrm{~mm}$, as illustrated in Fig. 9. As the gap between magnets is small, the force generated by the magnetic plucking is high. This is in accordance with Coulomb's Law, which states that magnetic force, $F$, is inversely proportional to the squared distance, $r^{2}$, between magnetic charges, as stated in the following equation:

$$
F=k_{e} \frac{q_{1} q_{2}}{r^{2}}
$$

In this equation, $k_{e}=9.0 \times 10^{9} \mathrm{~N} \mathrm{~m}^{2} \mathrm{C}^{-2}$, is Coulomb's constant, while $q_{1}$ and $q_{2}$ represent signed magnitudes of the magnetic charges. Thus, by decreasing the distances between the magnets, higher magnetic force will be achieved, which results in higher mechanical energy transduced into electrical energy. Therefore, higher output voltage is generated as compared to the other two readings having larger gaps between magnets. An attempt to reduce the gap even more resulted in the system being unstable due to too strong magnetic attraction.

The average peak voltage for D1 (magnets at $5 \mathrm{~mm}$ apart), D2 (magnets at $7.5 \mathrm{~mm}$ apart) and D3 (magnets at $10 \mathrm{~mm}$ apart) are as tabulated in Table 2. The measurements were taken five times, and the mean and standard deviations were calculated for voltages induced at magnet 1 to magnet 5 (M1, M2, M3, M4, and M5). The highest peak voltage recorded was $2.98 \mathrm{~V} \pm 0.03 \mathrm{~V}$ (mean \pm standard deviation), which was when the magnets were positioned at $5 \mathrm{~mm}$ apart. At distances of $7.5 \mathrm{~mm}$ and $10 \mathrm{~mm}$, the peak voltage produced were $1.76 \mathrm{~V} \pm 0.01 \mathrm{~V}$ and $0.34 \mathrm{~V} \pm 0.01 \mathrm{~V}$, respectively. The low standard 
deviation (below $5 \%$ of the mean) indicated that consistent voltage signals were generated by the energy harvester.

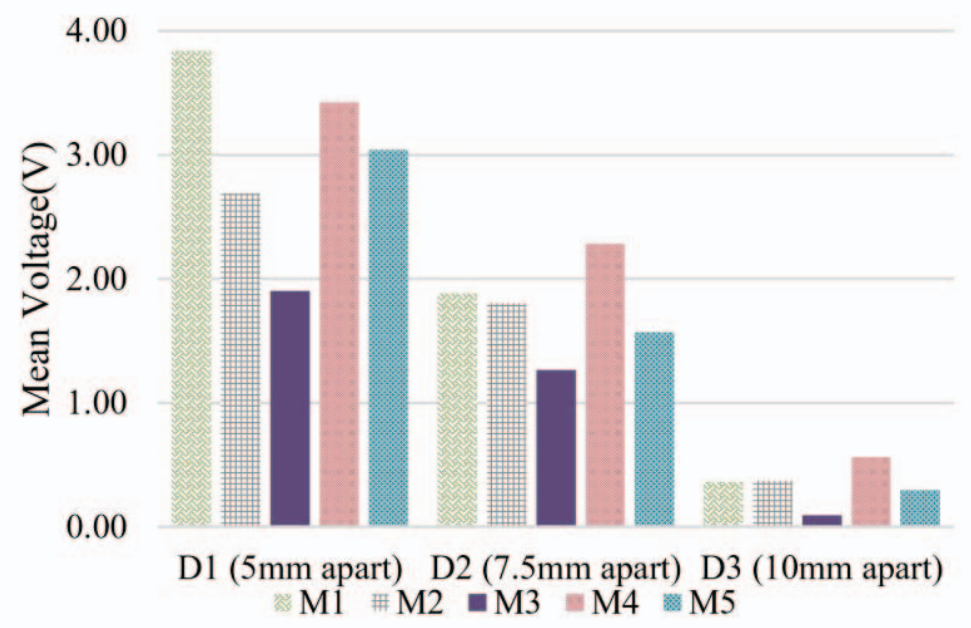

Fig. 9: Bar chart showing mean of voltage for respective distance and magnet number.

Table 2: Output voltage generated for different distances between magnets

\begin{tabular}{lcccccc}
\hline Magnet & \multicolumn{2}{c}{ D1 : $\mathbf{5} \mathbf{~ m m}$ apart, V } & \multicolumn{2}{c}{ D2 : 7.5 $\mathbf{~ m m}$ apart, V } & \multicolumn{2}{c}{ D3 : 10 $\mathbf{~ m m}$ apart, V } \\
\cline { 2 - 7 } & Mean & $\begin{array}{c}\text { Standard } \\
\text { deviation }\end{array}$ & Mean & $\begin{array}{c}\text { Standard } \\
\text { deviation }\end{array}$ & Mean & $\begin{array}{c}\text { Standard } \\
\text { deviation }\end{array}$ \\
\hline M1 & 3.84 & 0.040 & 1.88 & 0.004 & 0.36 & 0.005 \\
M2 & 2.69 & 0.037 & 1.80 & 0.006 & 0.37 & 0.008 \\
M3 & 1.90 & 0.023 & 1.27 & 0.013 & 0.09 & 0.005 \\
M4 & 3.43 & 0.020 & 2.28 & 0.010 & 0.56 & 0.006 \\
M5 & 3.04 & 0.031 & 1.57 & 0.006 & 0.30 & 0.004 \\
Average & 2.98 & 0.03 & 1.76 & 0.01 & 0.34 & 0.01 \\
\hline
\end{tabular}

It is worth noting that peak voltage induced was varied between all five magnets with standard deviations of $0.74 \mathrm{~V}, 0.38 \mathrm{~V}$, and $0.17 \mathrm{~V}$ for distances of $5 \mathrm{~mm}, 7.5 \mathrm{~mm}$, and 10 $\mathrm{mm}$, respectively. One of the reasons that may contribute to the deviation of voltage induced by these magnets is the variability of magnetic charges of each magnet, in which magnet M3 (middle magnet) has the lowest. This led to a lower magnetic force, $F$ that produced lower mechanical energy, which in turn, resulted in lower output voltage. Further investigation on this matter will be carried out in our future works.

It is also worth noting that there are also voltage signals in the other half cycle of the voltage output waveform. Referring back to Fig. 8, although comparatively lower than the voltage peaks produced by the magnetic plucking, these voltage signals were contributed by the hybrid kinetic motion of the eccentric mass rotor. The repetitive rotation of the rotor resulted in vibration to the piezoelectric beam, that produces some amount of voltage signals. Table 3 shows the peak voltage observed due to the hybrid kinetic motion. 
Table 3: Output voltage generated from hybrid kinetic motion

\begin{tabular}{cccc}
\hline Measurement & \multicolumn{3}{c}{ Observed Peak Voltage (V), at } \\
\cline { 2 - 4 } & $\begin{array}{c}\text { D1 } \\
\text { (5 mm apart) }\end{array}$ & $\begin{array}{c}\text { D2 (7.5 } \mathbf{~ m m} \\
\text { apart) }\end{array}$ & $\begin{array}{c}\text { D3 (10 } \mathbf{~ m m} \\
\text { apart) }\end{array}$ \\
\hline $\mathbf{1}$ & -1.95 & -1.11 & -0.67 \\
$\mathbf{2}$ & -1.97 & -1.1 & -0.66 \\
$\mathbf{3}$ & -1.98 & -1.14 & -0.67 \\
$\mathbf{4}$ & -1.98 & -1.14 & -0.66 \\
$\mathbf{5}$ & -1.9 & -1.14 & -0.67 \\
Mean & -1.966 & -1.122 & -0.666 \\
Standard Deviation & 0.034 & 0.018 & 0.005 \\
\hline
\end{tabular}

The highest voltage recorded due to the hybrid kinetic motion is $-1.966 \mathrm{~V} \pm 0.034 \mathrm{~V}$. Similar to the observation recorded via magnetic plucking, the standard deviation for the generated voltage is low, which indicates that the hybrid kinetic motion energy harvester is capable of producing a consistent output.

Since the voltage signals produced by the piezoelectric are in the AC form, it is pertinent that the signals are to be rectified and regulated into DC signals to ensure it could be properly utilized for electronic devices. By applying a precision full-wave rectifier that consists of an all-pass filter, a DC output voltage could be generated at almost the same level as its peak input voltage, with a very low ripple voltage [18]. This means that with this configuration, at least $2.5 \mathrm{~V}$ DC voltage could be harvested, which should be adequate in powering an electronic device. This part of work will be further investigated and implemented for further upgrade of the device.

Apart from that, since the power harvested from the piezoelectric is predictably less than the power consumption of the device, an energy storage element is a necessity. This can be done by connecting a diode bridge to the piezoelectric to rectify the output. The charge is transferred and stored in a tank capacitor, which is connected to the electronic system. In [20], a step-down DC-DC converter is employed after the tank capacitor and reported $325 \%$ harvested power as compared to when the battery is directly charged with the piezoelectric rectified source.

One way to increase the production of voltage output is to focus on the optimization of the kinetic motion such as employing spring mechanism, as that is the input and currently the bottleneck of the system. Modification on the beam design such as extending the beam with auxiliary polymer beam could also be done to lessen the stiffness of the beam, thus increasing the frequency of vibration of the beam.

Another approach is to combine the piezoelectric with the electromagnetic energy harvesting since the system already has moving magnets. Hybrid electromagnetic and piezoelectric systems exhibit high power output since the piezoelectric material produces high output voltage and low current. On the other hand, electromagnetic produces high output current and low output voltage [21-23]. 


\section{CONCLUSIONS}

This paper highlights the capability of a designed magnetically plucked piezoelectric energy harvester, with the aid of hybrid kinetic motion, to produce voltage output adequate enough to operate mobile or wearable electronic devices. With a maximum generated peak voltage of $2.98 \mathrm{~V} \pm 0.03 \mathrm{~V}$, this work shows promising implementation of an environmental-friendly and reliable clean energy generator.

Ideally, the rotation of the eccentric rotation mass should be through ambient sources instead of from a DC motor. Since low rotational speed from the DC motor was capable of producing such remarkable voltage output, human motion should be able to replace the electric power to operate the DC motor. The replication of the rotation motion on the eccentric rotation mass by human kinetic motion will be the next focus of this research work.

\section{ACKNOWLEDGEMENT}

The authors would like to thank the Smart Structures, Systems and Control Research Laboratory (S3C RL) of International Islamic University Malaysia for supporting this research work. This work is supported by the IIUM Research Initiative Grant Scheme (RIGS16-071-0235).

\section{REFERENCES}

[1] Priya S. (2007) Advances in energy harvesting using low profile piezoelectric transducers. J. Electroceramics, 19(1):165-182.

[2] Poulin G, Sarraute E, Costa F. (2004). Generation of electrical energy for portable devices: Comparative study of an electromagnetic and a piezoelectric system. Sensors Actuators A Phys, 116(3): 461-471.

[3] Pozzi M, Zhu M. (2011). Plucked piezoelectric bimorphs for knee-joint energy harvesting: modelling and experimental validation. Smart Mater. Struct., 20(5): 1-16.

[4] Pozzi M, Almond HJ, Leighton GJ, Morirarty RJ. (2015). Low-profile and wearable energy harvester based on plucked piezoelectric cantilevers. In Proceedings of Smart Sensors, Actuators, and MEMS VII: 4 - 6 May 2015; Barcelona. Edited by José L. Sánchez-Rojas, Riccardo Brama; pp 1-9.

[5] Kuang Y, Zhu M. (2017). Design study of a mechanically plucked piezoelectric energy harvester using validated finite element modelling. Sensors Actuators, A Phys., 263:510520 .

[6] Kuang Y, Yang Z, Zhu M. (2016). Design and characterisation of a piezoelectric knee-joint energy harvester with frequency up-conversion through magnetic plucking. Smart Mater. Struct., 25(8): 1-13.

[7] Kuang Y, Ruan T, Chew ZJ, Zhu M. (2017) Energy harvesting during human walking to power a wireless sensor node. Sensors Actuators, A Phys., 254: 69-77.

[8] Yeatman EM. Holmes AS, Pillatsch P. (2012) A scalable piezoelectric impulse-excited energy harvester for human body excitation. Smart Mater. Struct., 21(11).

[9] Asneh AGMA, Muthalif AGA, Wahid AN, JazlanA, Mohamad Hanif NHH. (2017) Piezoelectric based Broadband Nonlinear Vibration Energy Harvester using Multiple Magnets. Int. J. Ind. Electron. Electr. Eng., 5(12): 47-51.

[10] Arnold DP. (2007) Review of microscale magnetic power generation IEEE Trans. Magn., 43(11): 3940-3951.

[11] Pillatsch P, Yeatman EM, Holmes AS. (2013). A wearable piezoelectric rotational energy harvester. In Proceedings of IEEE Int. Conf. Body Sens. Networks: 6-9 May 2013; Cambridge, MA.

[12] Mohamad Hanif NHH, Jazlan Mohaideen A, Azam H, Rohaimi ME. (2018) Rotational 
piezoelectric energy harvester for wearable devices. Cogent Eng., 5(1):1-11.

[13] Mohamad Hanif NHH, Zain MZ, Rohaimie ME, Azam H. (2017). Power Estimation for Wearable Piezoelectric Energy Harvester. Telkomnika, 15(4): 101-106.

[14] Pozzi M. (2016). Magnetic plucking of piezoelectric bimorphs for a wearable energy harvester. Smart Mater. Struct., 25(4): 045008. doi: 10.1088/0964-1726/25/4/045008.

[15] Pozzi M, Zhu M. (2012). Characterization of a rotary piezoelectric energy harvester based on plucking excitation for knee-joint wearable applications. Smart Mater. Struct., 21(5): 05504.

[16] Lefeuvre E, Audigier D, Richard C, Guyomar D. (2007). Buck-boost converter for sensorless power optimization of piezoelectric energy harvester. IEEE Trans. Power Electron., 22(5): 2018-2025.

[17] H. Li, C. Tian, and Z. D. Deng. (2014). Energy harvesting from low frequency applications using piezoelectric materials. Appl. Phys. Rev., 1(4): 041301.

[18] Ralib AAM, Nordin AN, Salleh H. (2010). A comparative study on MEMS piezoelectric microgenerators. Microsyst Technol., 16(10):1673-1681.

[19] Graham BB. (2000). Using an Accelerometer Sensor to Measure Human Hand Motion. BSc. and MEng. thesis. Massachusetts Institute of Technology, Department of Electrical Engineering and Computer Science.

[20] Ottman GK, Hoffman HF, Lesieutre GA. (2002). Optimized Piezoelectric Energy Harvesting Circuit Using Step- down Converter in Discontinous Conduction Mode. IEEE Transducers Power Electron., 17(5):696-703.

[21] Hamid R, Yuce MR. (2017). A wearable energy harvester unit using piezoelectricelectromagnetic hybrid technique. Sensors Actuators, A Phys., 257: 198-207.

[22] Kwon DS, Ko HJ, Kim J. (2017). Piezoelectric and electromagnetic hybrid energy harvester using two cantilevers for frequency up-conversion. In Proceedings of IEEE Int. Conf. Micro Electro Mech. Syst.: 22-26 Jan 2017; Las Vegas. pp. 49-52.

[23] Li P, Gao S, Cai H. (2013). Modeling and analysis of hybrid piezoelectric and electromagnetic energy harvesting from random vibrations. Microsyst. Technol., 21(2):401414. 